\title{
Prognostic stratification of colorectal cancer patients: current perspectives
}

\author{
This article was published in the following Dove Press journal: \\ Cancer Management and Research \\ 2 July 2014 \\ Number of times this article has been viewed
}

\author{
Nora I Schneider \\ Cord Langner \\ Institute of Pathology, Medical \\ University of Graz, Graz, Austria
}

Correspondence: Cord Langner Institute of Pathology, Medical University of Graz, 25 Auenbruggerplatz, Graz, Styria 8036, Austria

Tel +43316385 I3665

$\mathrm{Fax}+43316385 \quad 13432$

Email cord.langner@medunigraz.at
Abstract: Tumor staging according to the American Joint Committee on Cancer/Union for International Cancer Control tumor, node, metastasis (TNM) system is currently regarded as the standard for staging of patients with colorectal cancer. This system provides the strongest prognostic information for patients with early stage disease and those with advanced disease. For patients with intermediate levels of disease, it is less able to predict disease outcome. Therefore, additional prognostic markers are needed to improve the management of affected patients. Ideal markers are readily assessable on hematoxylin and eosin-stained tumor slides, and in this way are easily applicable worldwide. This review summarizes the histological features of colorectal cancer that can be used for prognostic stratification. Specifically, we refer to the different histological variants of colorectal cancer that have been identified, each of these variants carrying distinct prognostic significance. Established markers of adverse outcomes are lymphatic and venous invasion, as well as perineural invasion, but underreporting still occurs in the routine setting. Tumor budding and tumor necrosis are recent advances that may help to identify patients at high risk for recurrence. The prognostic significance of the antitumor inflammatory response has been known for quite a long time, but a lack of standardization prevented its application in routine pathology. However, scales to assess intra- and peritumoral inflammation have recently emerged, and can be expected to strengthen the prognostic significance of the pathology report.

Keywords: colorectal cancer, lymphatic invasion, blood-vessel invasion, perineural invasion, tumor budding, tumor necrosis

\section{Introduction}

Tumor staging according to the American Joint Committee on Cancer (AJCC)/Union for International Cancer Control (UICC) tumor, node, metastasis (TNM) system is currently regarded as the standard for staging of colorectal cancer (CRC). The TNM classification provides the strongest prognostic information for patients with early stage disease and those with advanced disease. For patients with intermediate levels of disease, it is less able to predict disease outcome. ${ }^{1}$

In particular, patients with tumors of the same pathologic stage may experience considerably different clinical outcomes. ${ }^{1-3}$ Therefore, in patients with stage II CRC (pT3-pT4, N0, M0), supplemental risk estimation is crucial, because some patients may experience outcome inferior to stage III patients. Identification of these patients is important, as they might benefit from adjuvant therapy. ${ }^{4}$ Ideal histopathological prognostic markers are readily assessable on routine examination, ie, hematoxylin and eosin-stained slides. These markers could facilitate patient counseling and clinical decision making with respect to follow-up scheduling and administration of adjuvant therapy. 
In this review, we summarize the value of established and novel histopathological markers for the prognostication of patients with CRC (Table 1). Data for this review were compiled using Medline/PubMed and Thomson Reuters Web of Science, assessing articles published before April 2014. Search terms included colorectal cancer, histology, outcome, and prognostic factor. Only articles published in English were considered.

\section{Histopathological variants of colorectal cancer}

More than $90 \%$ of CRCs are adenocarcinomas. The World Health Organization classification of carcinomas of the colon and rectum lists several distinct histomorphological variant forms with a potential impact on prognosis. ${ }^{5}$

\section{Mucinous adenocarcinoma}

Mucinous adenocarcinoma constitutes 4\%-19\% of CRC worldwide. ${ }^{6-10}$ The designation is used when $>50 \%$ of the lesion is composed of pools of extracellular mucin that contain malignant epithelium as acinar structures, layers of tumor cells, or individual tumor cells including signet ring cells (Figure 1A). Carcinomas with mucinous areas of $<50 \%$ are categorized as having a mucinous component. ${ }^{5}$

The prognostic value of a mucinous histology in CRC remains controversial. Some studies have identified a significant association between mucinous histology and poor prognosis, ${ }^{6,9,11-13}$ while we and others could not confirm this observation. ${ }^{10,14}$ In a recent meta-analysis of 44 studies with a total of 222,256 patients, mucinous cancers more commonly originated from the right colon and were less frequent in male subjects. Mucinous differentiation resulted in a $2 \%-8 \%$ increased hazard of death, which persisted after correction for stage. ${ }^{15}$

In a large cohort comprising only patients with metastatic disease, patients with mucinous adenocarcinoma showed worse overall survival, progression-free survival (PFS), and overall response rate to chemotherapy compared to patients with conventional adenocarcinoma. ${ }^{11}$ Furthermore, patients with mucinous cancers were older and had larger tumor diameters, higher $\mathrm{T}$ classification, and increased likelihood of extrahepatic localization of metastases. ${ }^{11}$

Gao et $\mathrm{al}^{13}$ analyzed two independent databases and investigated the potential impact of primary tumor site on outcome. It is of interest that mucinous differentiation exhibited opposed prognostic effects depending on tumor location: mucinous histology was associated independently with poorer outcome for rectal cancer, and was an independent protective survival indicator in right-sided colon cancer. This may be due to the fact that right-sided mucinous adenocarcinomas are often microsatellite-unstable. ${ }^{16}$ Although the level of maturation of the epithelium determines differentiation, grading of mucinous cancers is (if at all) done mainly by molecular analysis: mucinous cancers that show high-level microsatellite instability (MSI-H) are considered low-grade, while those that are microsatellite-stable or show low-level MSI (MSI-L) are considered high-grade., ${ }^{5,15}$

To the best of our knowledge, there is only one study available that investigated the potential prognostic impact of a minor $(<50 \%)$ mucinous component. ${ }^{10}$ In this study, we hypothesized that cancers with a small amount of extracellular mucin may show differentiation arrest and behave as poorly differentiated mucinous cancers. However, no prognostic influence was seen in a retrospective analysis of 381 CRCs.

\section{Signet ring-cell carcinoma}

This variant is defined by the presence of $>50 \%$ of tumor cells with prominent intracytoplasmic mucin, typically with displacement and molding of the nucleus (Figure 1B). Signet-ring cells can occur within pools of mucinous adenocarcinoma or in a diffusely infiltrative process with minimal extracellular mucin in a linitis plastica pattern. Carcinomas with signet

Table I Established and novel histopathological markers for the prognostication of patients with colorectal cancer

\begin{tabular}{lll}
\hline & Markers of adverse & Markers of favorable \\
outcome & Micropapillary adenocarcinoma & \multicolumn{1}{c}{$\begin{array}{l}\text { Markers of limited value or } \\
\text { still unclear significance }\end{array}$} \\
\hline Sistopathological variants & Medullary carcinoma & \\
& Undifferentiated carcinoma & \\
Tumor-growth characteristics & Poor tumor differentiation & Inflammation at the invasive \\
and antitumor host response & Lymphatic invasion & tumor margin (Klintrup score) \\
& Venous invasion & Antitumor immune response \\
& Perineural invasion & (Ogino score) \\
& Tumor budding & Tumor-associated eosinophils \\
& Tumor necrosis & \\
\hline
\end{tabular}




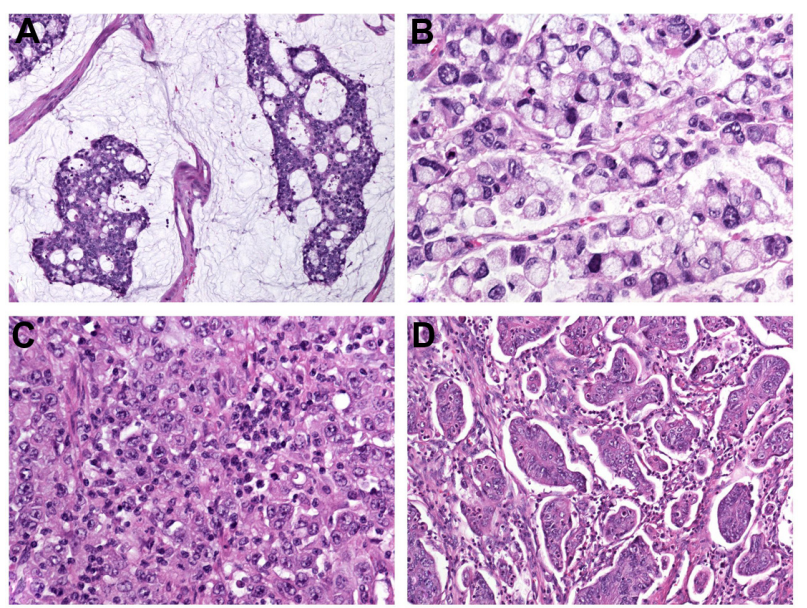

Figure I (A-D) Histopathological variants of colorectal cancer. (A) Mucinous adenocarcinoma characterized by abundant extracellular mucin production; (B) signet ring-cell carcinoma with prominent intracytoplasmic mucin deposition, causing displacement and molding of tumor-cell nuclei; (C) medullary carcinoma characterized by sheets of malignant cells with vesicular nuclei with prominent nucleoli and abundant eosinophilic cytoplasm (note prominent lymphocytic infiltration of the tumor tissue) (D) micropapillary adenocarcinoma with characteristic small papillary and trabecular tumor-cell clusters within stromal spaces mimicking vascular channels.

ring-cell areas of $<50 \%$ are categorized as adenocarcinoma with a signet ring-cell component. ${ }^{5}$

Overall, about $1 \%$ of CRCs are signet ring-cell carcinomas upon histology. ${ }^{12,17-19}$ In most studies, the prognostic value of signet ring-cell differentiation is evaluated in comparison to mucinous differentiation. Signet ring-cell carcinomas are more common on the right side, present at a higher tumor stage, and show a higher rate of lymphatic invasion and poorer differentiation. ${ }^{18-20}$

Signet ring-cell differentiation in CRC has been identified as an independent predictor of poor survival. ${ }^{17-19}$ Of note, tumors with signet ring-cell differentiation (and to a lesser extent also cancers with mucinous differentiation) have a propensity to cavitary metastatic spread with metastases to the peritoneum and ovaries. This is in contrast to conventional colorectal adenocarcinomas that metastasize predominantly to the liver and lungs. ${ }^{21}$

\section{Medullary carcinoma}

This rare variant is characterized by sheets of malignant cells with vesicular nuclei with prominent nucleoli and abundant eosinophilic cytoplasm (Figure 1C) exhibiting prominent infiltration by intraepithelial lymphocytes. ${ }^{5}$ Medullary carcinomas arise frequently in the proximal colon, with an incidence increasing with age and a female predominance. ${ }^{22,23}$

Patients usually present at stage II (without nodal metastasis). Medullary differentiation is an indicator of favorable prognosis: follow-up data showed 1- and 2- year survival rates of $92.7 \%$ and $73.8 \%$, respectively. ${ }^{23}$ On the molecular level, the majority of medullary carcinomas are MSI-H cancers. ${ }^{24}$

\section{Micropapillary adenocarcinoma}

Micropapillary adenocarcinoma is a rare tumor, and is defined by small papillary tumor cell clusters within stromal spaces mimicking vascular channels (Figure 1D). The pattern is mainly seen as a minor component of conventional adenocarcinoma. ${ }^{5}$ Upon immunohistochemistry, micropapillary adenocarcinoma shows a characteristic "inside-out" staining-pattern (reversed polarity, staining pointing toward the surrounding stroma) for MUC1 (EMA) and villin. ${ }^{25}$

Adenocarcinomas with a micropapillary component bear a high malignancy potential, with higher frequency of infiltrative pattern, lymphovascular and perineural invasion (PNI), deeper penetration into the bowel wall (ulcerated and/or stenosing tumors), and increased likelihood of positive lymph nodes compared to conventional adenocarcinomas. It is of note that already a small micropapillary component, such as $5 \%-10 \%$ of the tumor area, may significantly increase the risk of local $(40 \%-74 \%)$ and distant $(8 \%-16 \%)$ metastatic spread. ${ }^{25}$ Lino-Silva et al ${ }^{26}$ identified a micropapillary component in $10 \%$ of all colonic adenocarcinomas. Subserosal tissue invasion was present in every case, $60 \%$ was accompanied by poorly differentiated conventional adenocarcinoma, and $60 \%$ had more than four positive lymph nodes. In a study by Lee et al, ${ }^{27}$ micropapillary carcinomas were characterized by more frequent lymphovascular invasion $(P<0.001)$ and lymph-node metastasis $(P<0.001)$ and higher $\mathrm{T}$ classification and TNM stage ( $P=0.047$ and $P=0.001$, respectively), as well as more frequent expression of stem cell markers, such as $\operatorname{SOX} 2(P=0.038)$ and NOTCH3 $(P=0.005)$. The overall 5-year survival rate for patients with micropapillary carcinoma (37\%) was significantly lower than for patients with MSI-H and microsatellite-stable cancers lacking a micropapillary component $(92 \%$ and $72 \%, P<0.001$, respectively). The presence of a micropapillary carcinoma component was associated with poor survival in univariate $(P<0.001)$ and multivariate $(P=0.003$, Cox hazard ratio [HR] 2.402) analyses.

\section{Further histopathological variants}

Serrated adenocarcinoma has architectural similarity to a sessile serrated adenoma/polyp, and characteristically shows glandular serration that may be accompanied by mucinous, cribriform, and trabecular areas, as well as an absence of necrosis. The neoplastic cells have abundant eosinophilic 
cytoplasm, the condensed nuclei showing preserved polarity and low nucleus-to-cytoplasm ratio. ${ }^{5,28}$

Serrated adenocarcinoma accounts for about 7.5\%-9\% of all CRCs, particularly those developing through the "serrated pathway", which is characterized by BRAF mutations, cytosine-phosphate-guanine island methylation, and subsequent low- or high-level MSI. ${ }^{29,30}$ Serrated morphology has been associated with poor prognosis, particularly when occurring in left-sided tumors. ${ }^{30,31}$ Adenosquamous carcinoma has features of both squamous cell carcinoma and adenocarcinoma, either mixed or separate. ${ }^{5,32,33}$ This variant has been associated with a higher rate of metastasis at the time of operation (37\% versus $14 \%$ in conventional adenocarcinomas), and with high histological grade. Median overall survival time is significantly shorter compared to conventional adenocarcinoma (35.3 versus 82.4 months). In multivariate analysis, adenosquamous differentiation has been shown to be independently associated with increased overall and cancer-specific mortality. ${ }^{33}$

\section{Prognostic variables in colorectal cancer Lymph and blood-vessel invasion}

The invasion of tumor cells into lymph or blood vessels plays a crucial role in the metastatic process. Lymphatic invasion is diagnosed when tumor cells are present in vessels with an unequivocal endothelial lining, yet lacking a thick

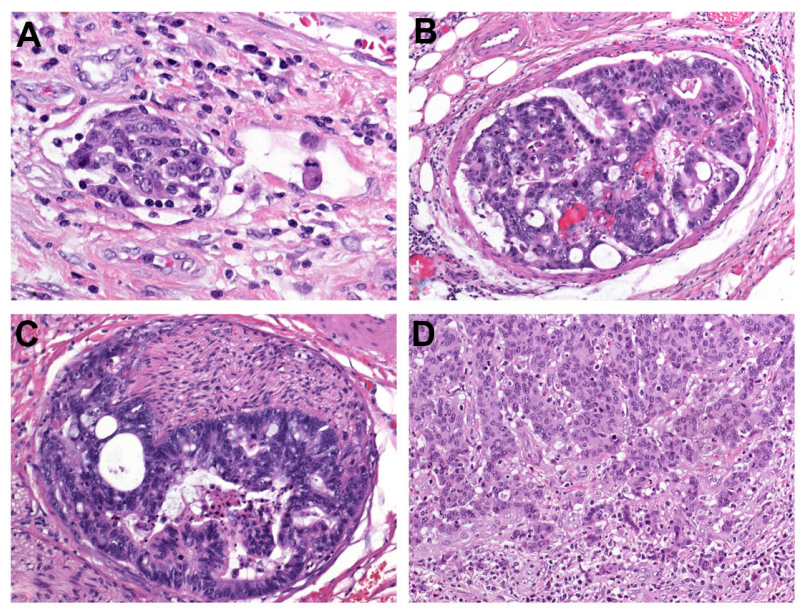

Figure 2 (A-D) Major prognostic variables in colorectal cancer. (A) Lymphatic invasion is diagnosed when tumor cells are present in vessels with an unequivocal endothelial lining, yet lacking a thick (muscular) wall; (B) blood vessel invasion refers to the involvement of veins, and is characterized histologically by the presence of tumor cells in vessels with a thick (muscular) wall or in vessels containing red blood cells; (C) perineural invasion is defined by tumor-cell invasion of nerves and/or spread along nerve sheaths; (D) tumor budding is characterized by the presence of isolated single cells or small clusters of cells composed of less than five cells scattered in the stroma at the invasive tumor margin. (muscular) wall (Figure 2A). Blood-vessel invasion refers to the involvement of veins, and is characterized histologically by the presence of tumor cells in vessels with a thick (muscular) wall or in vessels containing red blood cells (Figure 2B). Intramural vessel invasion, which is limited to vessels in the submucosal and/or muscular layer, has to be differentiated from extramural vessel invasion, which includes vessels located beyond the muscularis propria, ie, within the pericolic or perirectal adipose tissue.

In some studies, both lymph and blood-vessel invasion have been lumped together and referred to as "lymphovascular invasion" or simply as "vascular invasion", which is problematic, since the term "lymphovascular invasion" in other studies refers only to lymphatic invasion and the term "vascular invasion" only to venous invasion. ${ }^{34}$ All pathologists are well aware of the fact that discrimination between lymphatic channels and thin-walled postcapillary venules may be difficult. For this reason, the use of the terms "small vessels" instead of lymph vessels and "large vessels" instead of blood vessels has been suggested. ${ }^{34,35}$

Despite these problems, both lymph and blood-vessel invasion have emerged as major prognostic variables in patients with CRC, with significance in early and advanced lesions. ${ }^{1,36,37}$ Consequently, both the Association of Directors of Anatomic and Surgical Pathology ${ }^{38}$ and the College of American Pathologists ${ }^{39}$ emphasize the recording of vascular invasion during routine pathological work-up of cancer specimens. These bodies stress that invasion of extramural veins is an independent predictor of unfavorable outcome and increased risk of hepatic metastasis, while the significance of intramural venous (as well as lymphatic) invasion is less clear. It is of note that in the most recent College of American Pathologists' cancer-reporting protocol, ${ }^{39}$ venous invasion is not recorded separately from lymphovascular or "small vessel" invasion, which may not be appropriate, because these features confer differing prognostic information. ${ }^{40}$

In our own retrospective investigation of $381 \mathrm{CRCs}$, patients with and without venous invasion had actuarial 5 -year cancer-specific survival (CSS) rates of $30 \%$ and $75 \%$, respectively. Regarding vessel location, $46 \%$ of patients with intramural venous invasion and $77 \%$ with extramural venous invasion died of disease progression $(P<0.001)$. Comparable results were noted for intramural and extramural lymphatic invasion ( $35 \%$ versus $64 \%, P<0.001)$. In multivariate analysis, the prognostic impact of venous invasion was comparable to that of $\mathrm{T}$ classification, stronger than that of tumor grade and lymphatic invasion, yet inferior to that of lymph-node metastasis. When analysis was restricted to patients with 
AJCC/UICC stage II tumors, venous invasion proved to be the only prognostic variable with respect to both PFS $(P=0.011)$ and $\operatorname{CSS}(P=0.006) .{ }^{41}$ In node-positive tumors, lymphatic invasion can be identified in only about $50 \%$ of cases. The prognostic significance of lymphatic invasion is however limited in this subgroup: $\mathrm{T}$ and $\mathrm{N}$ classification, as well as tumor differentiation, are the major variables for prognostication, and merit special attention in patient counseling and decision making. ${ }^{42}$

Venous invasion is widely believed to be an underreported finding, with significant variability in its reported incidence. ${ }^{40}$ However, accurate assessment is crucial and of particular importance in stage II disease, because it may influence the decision to administer adjuvant therapy. In our study, prognostication by review pathology was superior to routine pathology, and both false-positive (mainly due to the overestimation of retraction artifacts) and false-negative diagnoses may occur. ${ }^{41}$ Some authors stressed that the diagnosis of vascular involvement may be improved by applying ancillary techniques, such as Elastica van Gieson and immunostaining for cluster of differentiation (CD)31 and D2-40 for the detection of endothelial cells, as well as $\alpha$-smoothmuscle actin for the detection of vessel walls..$^{35,43}$

\section{Perineural invasion}

PNI is defined by tumor-cell invasion of nervous structures, as illustrated by neoplastic invasion of nerves and/or spread along nerve sheaths (Figure 2C). ${ }^{44,45}$ In some neoplasms, in particular pancreatic and prostate adenocarcinomas, PNI has been recognized as a characteristic histological feature. ${ }^{5,46}$ Its presence constitutes a process for neoplastic invasion and cancer spread, independent of blood and lymphatic vessels. In the pathogenesis of PNI, neurotropic factors and matrix metalloproteinases seem to be involved. ${ }^{45}$

The prognostic significance of PNI in CRC has been investigated by several groups. Liebig et $\mathrm{al}^{46}$ reported fourfold-greater 5-year disease-free survival rates for patients with PNI-negative cancers compared to patients with PNI-positive cancers $(65 \%$ versus $16 \%, P<0.001)$. Our own investigation brought similar results: the presence of PNI was associated with an aggressive tumor phenotype, as shown by significant associations with lymph and blood-vessel invasion, tumor-growth pattern, and budding, as well as poor tumor differentiation. ${ }^{47}$ Multivariate analysis identified PNI as a prognostic variable in both tumor locations, ie, for the colon (PFS HR 3.11, 95\% confidence interval [CI] 1.72-5.63, $P<0.001$; CSS HR 3.03, 95\% CI 1.51-6.05, $P=0.002$ ) and rectum (PFS HR 1.84, 95\% CI
1.00-3.37, $P=0.05$; CSS HR 1.93, 95\% CI 1.02-3.65, $P=0.04$ ) cancers. ${ }^{47}$

PNI seems to have an independent influence on local tumor recurrence in rectal cancer. In a study by Peng et al, ${ }^{48}$ patients with PNI-positive node-negative tumors (T3 N0) had a 2.5-fold higher 5-year local recurrence rate than PNI-negative tumors $(22.7 \%$ versus $7.9 \%)$. We demonstrated that in rectal cancers with tumor-free resection margins (R0 resection), PNI was the only independent predictor of local tumor progression (HR 5.62, 95\% CI 1.97-15.99; $P=0.001$ ). ${ }^{47}$

Recently, Ueno et $\mathrm{al}^{49}$ introduced a three-tiered grading system for PNI (no PNI, intramural PNI, extramural PNI) with 5 -year disease-free survival rates of $88 \%, 70 \%$, and $48 \%$, respectively. In multivariate analysis, the site of PNI was shown to be a significant prognostic variable, independent of $\mathrm{T}$ and $\mathrm{N}$ classification. Future studies are warranted to validate these findings.

\section{Tumor budding}

Tumor budding has been defined as the presence of isolated single cells or small clusters of cells composed of fewer than five cells. These tumor buds are scattered in the stroma at the invasive tumor margin (Figure 2D), with a tendency to lose coherence and detach as single cells, thereby representing tumor aggressiveness. ${ }^{50-52}$ Biologically, tumor budding is closely related to the process of epithelial-mesenchymal transition. During this transition, epithelial cells lose intercellular and cell-matrix contacts mediated by E-cadherin, and the tumor-cell complexes dissociate, promoting invasion and ultimately metastatic cancer spread. ${ }^{53}$ But cancer cells do not only lose epithelial properties during this process they may modify their epithelial phenotype by aberrant (de novo) expression of epithelial markers such as keratin 7 . The term "epithelial-epithelial transition" has been suggested by our group for this hitherto unrecognized basic principle of invasion. ${ }^{54}$

In several studies, tumor budding has been presented as a prognostic variable in CRC, independently predicting poor survival $^{51,55-58}$ and high risk of recurrence. ${ }^{59-61}$ Nakamura et $\mathrm{al}^{62}$ analyzed 200 patients with colon cancer, and identified tumor budding as the strongest independent predictor of cancer-related death, while venous and lymphatic invasion did not have independent prognostic influence.

Although budding currently appears to be the most interesting prognostic variable in $\mathrm{CRC}$, it has often been criticized, because of nonstandardized criteria for evaluation and unclear reproducibility of the numerous methods for tumor-budding measurement. ${ }^{63}$ Recently, Karamitopoulou et $\mathrm{al}^{64}$ presented 
a promising 10-high-power field method for assessment of tumor budding. This method showed excellent interobserver agreement and proved independent prognostic value. According to this proposal, high-grade budding can be defined as an average of ten or more buds across 10-high-power fields, and was associated with higher tumor grade $(P<0.0001)$, vascular invasion $(P<0.0001)$, infiltrating tumor-border configuration $(P<0.0001)$, higher TNM stage $(P=0.0003)$, and reduced survival $(P<0.0001)$. Multivariate analysis confirmed an independent prognostic effect of tumor budding $(P=0.007)$ when adjusted for TNM stage and adjuvant therapy. ${ }^{64}$

Tumor budding is of interest also in distinct subgroups of CRC. In early lesions, it appears to be one of the strongest parameters associated with the presence of regional lymphnode spread. ${ }^{36,37}$ In patients with AJCC/UICC stage II disease, the extent of tumor budding could be used to select patients with node-negative cancers for adjuvant therapy. ${ }^{50,65-67}$

Very recently, Rogers et al ${ }^{68}$ presented data from patients with locally advanced rectal cancer who underwent neoadjuvant chemoradiation. In these patients, intratumoral budding assessed on pretherapeutic biopsies predicted poor pathological response to neoadjuvant treatment and poor prognosis.

In 2012 , Ueno et $\mathrm{al}^{69}$ proposed a new grading system for CRC based upon the quantification of "poorly differentiated clusters". These are defined as clusters of five or more cancer cells infiltrating the stroma at the invasive tumor margin, lacking gland-like structures. Poorly differentiated clusters affected survival outcome independent of $\mathrm{T}$ and $\mathrm{N}$ classification. The prognostic value of poorly differentiated clusters was confirmed by two additional publications by the same group of authors ${ }^{70,71}$ and also by another group. ${ }^{72,73}$

Morphologically, poorly differentiated clusters are closely related to tumor budding (the nests are slightly larger) and also to the micropapillary variant of CRC, as can easily be extracted from the images provided in the respective publication. ${ }^{69}$ Future studies are needed to prove the originality of poorly differentiated clusters as a histological feature as well as a prognostic variable.

\section{Tumor necrosis}

Coagulative tumor necrosis (Figure 3A) is a common feature in multiple solid tumors, especially in lung ${ }^{74}$ and renal cell carcinoma, ${ }^{75}$ as well as upper urinary tract urothelial carcinoma, ${ }^{76,77}$ but studies assessing the prognostic value of tumor necrosis in CRC are rare. Tumor necrosis is believed to be a consequence of chronic ischemic injury, due to rapid tumor growth and thereby reflecting the level of intratumoral
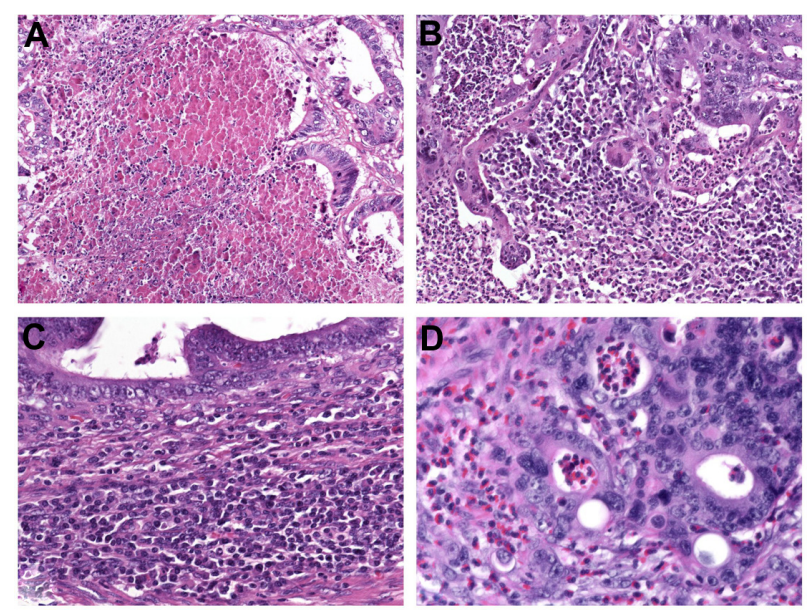

Figure 3 (A-D) Additional prognostic variables in colorectal cancer. (A) Coagulative tumor necrosis reflecting chronic ischemic injury due to rapid tumor growth. Assessing the anti-tumoral inflammatory response is another novel prognostic tool which commonly indicates favorable outcome. (B) Marked overall inflammation at the tumor margin, characterized by a mixed inflammatory infiltrate with destruction of cancer-cell islets. (C) Antitumor immune response, characterized by dense peritumoral lymphocytic infiltration; (D) Eosinophilic infiltration of the tumor area (tumor-associated tissue eosinophilia).

hypoxia. ${ }^{74,76}$ Increased cellular hypoxia correlates with increased metastatic potential and worse prognosis, as well as resistance to radiotherapy and chemotherapy ${ }^{74-77}$

In our investigation, the extent of necrosis was significantly associated with $\mathrm{T}$ classification $(P<0.001)$, N classification $(P=0.005)$, TNM stage $(P<0.001)$, poor tumor differentiation $(P<0.001)$, large tumor size $(P<0.001)$, and presence of blood-vessel invasion $(P=0.01){ }^{78} \mathrm{CRC}$ patients with tumors with moderate $(10 \%-30 \%$ of the tumor area) or extensive ( $>30 \%$ of the tumor area) necrosis were more likely to develop disease progression $(P<0.001)$, and actuarial 5 -year CSS rates for patients with tumors lacking necrosis and those showing focal ( $<10 \%$ of the tumor area) necrosis, moderate necrosis, or extensive necrosis were $93 \%, 74 \%$, $60 \%$, and $42 \%$, respectively. Tumor necrosis was identified as an independent predictor of PFS and CSS in multivariate analysis. $^{78}$

Our findings were validated by other groups. ${ }^{79-81}$ It is of interest that Richards et a $7^{79,80}$ noted a relationship between tumor necrosis and the host systemic and local inflammatory response (intra/peritumoral inflammatory infiltrate). In a subsequent publication, the authors provided supportive evidence for the hypothesis that tumor necrosis is associated with elevated circulating interleukin (IL)-6 and vascular endothelial growth factor (VEGF) concentrations, thereby modulating both local and systemic inflammatory responses, as well as angiogenesis, which in turn may promote tumor progression and metastasis. ${ }^{82}$ 


\section{Inflammatory response}

The antitumoral inflammatory response is a distinct histological feature and promising prognostic tool in CRC pathology. Several topics need to be addressed: the overall inflammatory response at the tumor margin, the antitumor immune response, characterized by lymphocytic infiltration, and the infiltration of the tumor stroma by eosinophils and macrophages.

The predictive value of the inflammatory cell reaction is already part of the Jass and Morson classification, ${ }^{83}$ dating from 1987. Today, Klintrup's criteria ${ }^{84}$ are widely used for scoring the intensity of inflammation at the invasive margin. This is done using a four-degree scale that takes into consideration the numbers of neutrophilic and eosinophilic granulocytes, lymphoid cells, and macrophages and their relation to the invading tumor (with or without destruction of cancer-cell islets) (Figure 3B). Klintrup et a ${ }^{84}$ demonstrated that high-grade inflammation at the invasive margin in node-negative $\mathrm{CRC}$ is associated with better 5-year-survival compared to low-grade inflammation ( $87.6 \%$ versus $47.0 \%$, $P<0.0001)$. The beneficial effect of high peritumoral inflammation according to Klintrup's criteria was confirmed in several studies. . $9,85,86^{\circ}$

Ogino et a ${ }^{87}$ developed a scoring system for the antitumor immune response, based upon the evaluation of four distinct features: tumor-infiltrating lymphocytes, lymphocytic infiltration of the intra- and peritumoral stroma, and Crohn's-like lymphoid reaction (Figure 3C). The lymphocytic antitumor immune response has been associated with an MSI-H phenotype $^{88,89}$ and favorable prognosis in several studies. ${ }^{90-93}$ Recent data suggest that specific immunotyping of the lymphocytic infiltrate ("immunoscore") may be of additional prognostic value, ${ }^{94,95}$ in particular if assessed together with tumor budding. ${ }^{96}$

Eosinophilic infiltration in the tumor area, which is also called tumor-associated tissue eosinophilia, is an easily assessable parameter in routine pathology (Figure 3D). Increased numbers of eosinophils have been favorably associated with disease recurrence and survival in patients with CRC. . $^{90,97,98}$

The role of macrophages seems to be more complex, because they have been attributed both pro- and antitumor properties. ${ }^{99}$ However, a high number of CD68-positive tumor-associated macrophages have been identified as a favorable morphological feature. ${ }^{100,101}$

\section{Conclusion}

Although tumor staging according to the AJCC/UICC TNM system is currently regarded as the standard for staging of patients with CRC, this system seems not to be suitable to predict outcome in patients with intermediate levels of disease. Ideal prognostic markers are readily assessable on hematoxylin and eosin-stained tumor slides, and are in this way easily applicable worldwide. Markers that can be used to identify patients at high risk for recurrence who might benefit from adjuvant therapy include distinct histological variants, in particular signet ring-cell carcinoma and micropapillary adenocarcinoma, but also lymphatic invasion, venous invasion, perineural invasion, and a high degree of tumor budding and tumor necrosis. Markers that have been associated with favorable outcome include the medullary variant of CRC, a high degree of antitumor host response (overall inflammation at the invasion margin, lymphocytic infiltration, and tumor-associated eosinophils), as well as the documented absence of markers indicating poor outcome. Currently, many of these markers are underreported, but pathologists need to address them in their routine reports, as they may be used for prognostication of affected individuals and are relevant for clinical decision making in the multidisciplinary team.

\section{Disclosure}

The authors report no conflicts of interest in this work.

\section{References}

1. Compton CC. Optimal pathologic staging: defining stage II disease. Clin Cancer Res. 2007;13(22 Pt 2):6862s-6870s.

2. McLeod HL, Murray GI. Tumour markers of prognosis in colorectal cancer. Br J Cancer. 1999;79(2):191-203.

3. Lyall MS, Dundas SR, Curran S, Murray GI. Profiling markers of prognosis in colorectal cancer. Clin Cancer Res. 2006;12(4):1184-1191.

4. O'Connell JB, Maggard MA, Ko CY. Colon cancer survival rates with the new American Joint Committee on Cancer sixth edition staging. J Natl Cancer Inst. 2004;96(19):1420-1425.

5. Hamilton SR, Bosman FT, Boffetta P, et al. Carcinoma of the colon and rectum. In: Bosman FT, Carneiro F, Hruban RH, Theise ND, editors. WHO Classification of Tumours of the Digestive System. 4th ed. Lyon: IARC; 2010:134-146.

6. Du W, Mah JT, Lee J, Sankila R, Sankaranarayanan R, Chia KS. Incidence and survival of mucinous adenocarcinoma of the colorectum: a population-based study from an Asian country. Dis Colon Rectum. 2004;47(1);78-85.

7. Stewart SL, Wike JM, Kato I, Lewis DR, Michaud F. A populationbased study of colorectal cancer histology in the United States, 1998-2001. Cancer. 2006;107(Suppl 5):1128-1141.

8. Xie L, Villeneuve PJ, Shaw A. Survival of patients diagnosed with either colorectal mucinous or non-mucinous adenocarcinoma: a populationbased study in Canada. Int J Oncol. 2009;34(4);1109-1115.

9. Chew MH, Yeo SA, Ng ZP, et al. Critical analysis of mucin and signet ring cell as prognostic factors in an Asian population of 2,764 sporadic colorectal cancers. Int J Colorect Dis. 2010;25(10);1221-1229.

10. Langner C, Harbaum L, Pollheimer MJ, et al. Mucinous differentiation in colorectal cancer - indicator of poor prognosis? Histopathology 2012;60(7):1060-1072.

11. Mekenkamp LJ, Heesterbeek KJ, Koopman M, et al. Mucinous adenocarcinomas: poor prognosis in metastatic colorectal cancer. Eur J Cancer. 2012;48(4):501-509. 
12. Hyngstrom JR, Hu CY, Xing Y, et al. Clinicopathology and outcomes for mucinous and signet ring colorectal adenocarcinoma: analysis from the National Cancer Data Base. Ann Surg Oncol. 2012;19(9):2814-2821.

13. Gao P, Song YX, Xu YY, et al. Does the prognosis of colorectal mucinous carcinoma depend upon the primary tumour site? Results from two independent databases. Histopathology. 2013;63(5):603-615.

14. Compton C, Fenoglio-Preiser CM, Pettigrew N, Fielding LP. American Joint Committee on Cancer Prognostic Factors Consensus Conference: Colorectal Working Group. Cancer. 2000;88(7);1739-1757.

15. Verhulst J, Ferdinande L, Demetter P, Ceelen W. Mucinous subtype as prognostic factor in colorectal cancer: a systematic review and meta-analysis. J Clin Pathol. 2012;65(5):381-388.

16. Minoo P, Zlobec I, Peterson M, Terracciano L, Lugli A. Characterization of rectal, proximal and distal colon cancers based on clinicopathological, molecular and protein profiles. Int J Oncol. 2010;37(3): 707-718.

17. Kang H, O’Connell JB, Maggard MA, Sack J, Ko CY. A 10-year outcomes evaluation of mucinous and signet-ring cell carcinoma of the colon and rectum. Dis Colon Rectum. 2005;48(6):1161-1168.

18. Nitsche U, Zimmermann A, Späth C, et al. Mucinous and signet-ring cell colorectal cancers differ from classical adenocarcinomas in tumor biology and prognosis. Ann Surg. 2013;258(5):775-782; discussion 782-783.

19. Thota R, Fang X, Subbiah S. Clinicopathological features and survival outcomes of primary signet ring cell and mucinous adenocarcinoma of colon: retrospective analysis of VACCR database. $J$ Gastrointest Oncol. 2014;5(1):18-24.

20. Sung CO, Seo JW, Kim KM, Do IG, Kim SW, Park CK. Clinical significance of signet-ring cells in colorectal mucinous adenocarcinoma. Mod Pathol. 2008;21(12):1533-1541.

21. Pande R, Sunga A, Levea C, et al. Significance of signet-ring cells in patients with colorectal cancer. Dis Colon Rectum. 2008;51(1): $50-55$.

22. Wick MR, Vitsky JL, Ritter JH, Swanson PE, Mills SE. Sporadic medullary carcinoma of the colon: a clinicopathologic comparison with nonhereditary poorly differentiated enteric-type adenocarcinoma and neuroendocrine colorectal carcinoma. Am J Clin Pathol. 2005;123(1): $56-65$.

23. Thirunavukarasu P, Sathaiah M, Singla S, et al. Medullary carcinoma of the large intestine: a population based analysis. Int J Oncol. 2010;37(4): 901-907.

24. Chetty R. Gastrointestinal cancers accompanied by a dense lymphoid component: an overview with special reference to gastric and colonic medullary and lymphoepithelioma-like carcinomas. J Clin Pathol. 2012;65(12):1062-1065.

25. Verdú M, Román R, Calvo M, et al. Clinicopathological and molecular characterization of colorectal micropapillary carcinoma. Mod Pathol. 2011;24(5):729-738.

26. Lino-Silva LS, Salcedo-Hernández RA, Caro-Sánchez CH. Colonic micropapillary carcinoma, a recently recognized subtype associated with histological adverse factors: clinicopathological analysis of 15 cases. Colorectal Dis. 2012;14(9):e567-e572.

27. Lee HJ, Eom DW, Kang GH, et al. Colorectal micropapillary carcinomas are associated with poor prognosis and enriched in markers of stem cells. Mod Pathol. 2013;26(8):1123-1131.

28. Tuppurainen K, Mäkinen JM, Junttila $\mathrm{O}$, et al. Morphology and microsatellite instability in sporadic serrated and non-serrated colorectal cancer. J Pathol. 2005;207(3):285-294.

29. Mäkinen MJ. Colorectal serrated adenocarcinoma. Histopathology. 2007;50(1):131-150.

30. García-Solano J, Pérez-Guillermo M, Conesa-Zamora P, et al. Clinicopathologic study of 85 colorectal serrated adenocarcinomas: further insights into the full recognition of a new subset of colorectal carcinoma. Hum Pathol. 2010;41(10):1359-1368.

31. Shida Y, Fujimori T, Tanaka H, et al. Clinicopathological features of serrated adenocarcinoma defined by Mäkinen in Dukes' B colorectal carcinoma. Pathobiology. 2012;79(4):169-174.
32. Petrelli NJ, Valle AA, Weber TK, Rodriguez-Bigas M. Adenosquamous carcinoma of the colon and rectum. Dis Colon Rectum. 1996;39(11): $1265-1268$.

33. Masoomi H, Ziogas A, Lin BS, et al. Population-based evaluation of adenosquamous carcinoma of the colon and rectum. Dis Colon Rectum. 2012;55(5):509-514.

34. Betge J, Langner C. Vascular invasion, perineural invasion, and tumour budding: predictors of outcome in colorectal cancer. Acta Gastroenterol Belg. 2011;74(4):516-529.

35. van Wyk HC, Roxburgh CS, Horgan PG, et al. The detection and role of lymphatic and blood vessel invasion in predicting survival in patients with node negative operable primary colorectal cancer. Crit Rev Oncol Hematol. 2014;90(1):77-90.

36. Beaton C, Twine CP, Williams GL, et al. Systematic review and metaanalysis of histopathological factors influencing the risk of lymph node metastasis in early colorectal cancer. Colorectal Dis. 2013;15(7): 788-797.

37. Bosch SL, Teerenstra S, de Wilt JH, et al. Predicting lymph node metastasis in pT1 colorectal cancer: a systematic review of risk factors providing rationale for therapy decisions. Endoscopy. 2013;45(10): 827-834.

38. Jass JR, O'Brien J, Riddell RH, et al. Recommendations for the reporting of surgically resected specimens of colorectal carcinoma: Association of Directors of Anatomic and Surgical Pathology. Am J Clin Pathol. 2008;129(1):13-23.

39. Washington MK, Berlin J, Branton P, et al. Protocol for the examination of specimens from patients with primary carcinoma of the colon and rectum. Arch Pathol Lab Med. 2009;133(10):1539-1551.

40. Messenger DE, Driman DK, Kirsch R. Developments in the assessment of venous invasion in colorectal cancer: implications for future practice and patient outcome. Hum Pathol. 2012;43(7):965-973.

41. Betge J, Pollheimer MJ, Lindtner RA, et al. Intramural and extramural vascular invasion in colorectal cancer: prognostic significance and quality of pathology reporting. Cancer. 2012;118(3):628-638.

42. Betge J, Schneider NI, Pollheimer MJ, et al. Is there a rationale to record lymphatic invasion in node-positive colorectal cancer? J Clin Pathol. 2012;65(9):847-850.

43. Harris EI, Lewin DN, Wang HL, et al. Lymphovascular invasion in colorectal cancer: an interobserver variability study. Am J Surg Pathol. 2008;32(12):1816-1821.

44. Batsakis JG. Nerves and neurotropic carcinomas. Ann Otoln Rhinol Laryngol. 1985;94(4 Pt 1):426-427.

45. Liebig C, Ayala G, Wilks JA, Berger DH, Albo D. Perineural invasion in cancer: a review of the literature. Cancer. 2009;115(15):3379-3391.

46. Liebig C, Ayala G, Wilks J, et al. Perineural invasion is an independent predictor of outcome in colorectal cancer. J Clin Oncol. 2009;27(31): 5131-5137.

47. Poeschl EM, Pollheimer MJ, Kornprat P, et al. Perineural invasion: correlation with aggressive phenotype and independent prognostic variable in both colon and rectum cancer. $J$ Clin Oncol. 2010;28(21): e358-e360; author reply e361-e362.

48. Peng J, Sheng W, Huang D, et al. Perineural invasion in pT3N0 rectal cancer: the incidence and its prognostic effect. Cancer. 2011;117(7): 1415-1421.

49. Ueno H, Shirouzu K, Eishi Y, et al. Characterization of perineural invasion as a component of colorectal cancer staging. Am J Surg Pathol. 2013;37(10):1542-1549.

50. Hase K, Shatney C, Johnson D, Trollope M, Vierra M. Prognostic value of tumor "budding" in patients with colorectal cancer. Dis Colon Rectum. 1993;36(7):627-635.

51. Ueno H, Murphy J, Jass JR, Mochizuki H, Talbot IC. Tumour 'budding' as an index to estimate the potential of aggressiveness in rectal cancer. Histopathology. 2002;40(2):127-132.

52. Ueno H, Mochizuki H, Hashiguchi Y, et al. Risk factors for an adverse outcome in early invasive colorectal carcinoma. Gastroenterology. 2004;127(2):385-394.

53. LugliA, Karamitopoulou E, Zlobec I. Tumour budding: a promising parameter in colorectal cancer. Br J Cancer. 2012;106(11):1713-1717. 
54. Harbaum L, Pollheimer MJ, Kornprat P, Lindtner RA, Schlemmer A, Rehak P, Langner C. Keratin 7 expression in colorectal cancerfreak of nature or significant finding? Histopathology. 2011;59(2): 225-234.

55. Okuyama T, Nakamura T, Yamaguchi M. Budding is useful to select high-risk patients in stage II well-differentiated or moderately differentiated colon adenocarcinoma. Dis Colon Rectum. 2003;46(10): 1400-1406.

56. Ueno H, Price AB, Wilkinson KH, Jass JR, Mochizuki H, Talbot IC. A new prognostic staging system for rectal cancer. Ann Surg. 2004;240(5):832-839.

57. Kanazawa $\mathrm{H}$, Mitomi $\mathrm{H}$, Nishiyama $\mathrm{Y}$, et al. Tumour budding at invasive margins and outcome in colorectal cancer. Colorectal Dis. 2008;10(1): $41-47$.

58. Zlobec I, Terracciano L, Tornillo L, et al. Role of RHAMM within the hierarchy of well-established prognostic factors in colorectal cancer. Gut. 2008;57(10):1413-1419.

59. Park KJ, Choi HJ, Roh MS, Kwon HC, Kim C. Intensity of tumor budding and its prognostic implications in invasive colon carcinoma. Dis Colon Rectum. 2005;48(8):1597-1602.

60. Choi HJ, Park KJ, Shin JS, Roh MS, Kwon HC, Lee HS. Tumor budding as a prognostic marker in stage-III rectal carcinoma. Int $J$ Colorectal Dis. 2007;22(8):863-868.

61. Ohtsuki K, Koyama F,TamuraT. Prognostic value of immunohistochemical analysis of tumor budding in colorectal carcinoma. Anticancer Res. 2008;28(3B):1831-1836.

62. Nakamura T, Mitomi H, Kanazawa H, Ohkura Y, Watanabe M. Tumor budding as an index to identify high-risk patients with stage II colon cancer. Dis Colon Rectum. 2008;51(5):568-572.

63. Quirke P, Risio M, Lambert R, von Karsa L, Vieth M. Quality assurance in pathology in colorectal cancer screening and diagnosis - European recommendations. Virchows Arch. 2011;458(1):1-19.

64. Karamitopoulou E, Zlobec I, Kölzer V, et al. Proposal for a 10-highpower-fields scoring method for the assessment of tumor budding in colorectal cancer. Mod Pathol. 2013;26(2):295-301.

65. Betge J, Kornprat P, Pollheimer MJ, et al. Tumor budding is an independent predictor of outcome in AJCC/UICC stage II colorectal cancer. Ann Surg Oncol. 2012;19(12):3706-3712.

66. Mitrovic B, Schaeffer DF, Riddell RH, Kirsch R. Tumor budding in colorectal carcinoma: time to take notice. Mod Pathol. 2012;25(10): 1315-1325.

67. Horcic M, Koelzer VH, Karamitopoulou E, et al. Tumor budding score based on 10 high-power fields is a promising basis for a standardized prognostic scoring system in stage II colorectal cancer. Hum Pathol. 2013;44(5):697-705.

68. Rogers AC, Gibbons D, Hanly AM, et al. Prognostic significance of tumor budding in rectal cancer biopsies before neoadjuvant therapy. Mod Pathol. 2014;27(1):156-162.

69. Ueno H, Kajiwara Y, Shimazaki H, et al. New criteria for histologic grading of colorectal cancer. Am J Surg Pathol. 2012;36(2): 193-201.

70. Ueno H, Hase K, Hashiguchi Y, et al. Novel risk factors for lymph node metastasis in early invasive colorectal cancer: a multi-institution pathology review. J Gastroenterol. Epub September 25, 2013.

71. Ueno H, Hase K, Hashiguchi Y, et al. Site-specific tumor grading system in colorectal cancer: multicenter pathologic review of the value of quantifying poorly differentiated clusters. Am J Surg Pathol. 2014;38(2):197-204

72. Barresi V, Reggiani Bonetti L, Branca G, Di Gregorio C, Ponz de Leon M, Tuccari G. Colorectal carcinoma grading by quantifying poorly differentiated cell clusters is more reproducible and provides more robust prognostic information than conventional grading. Virchows Arch. 2012;461(6):621-628

73. Barresi V, Bonetti LR, Ieni A, Branca G, Baron L, Tuccari G. Histologic grading based on counting poorly differentiated clusters in preoperative biopsy predicts nodal involvement and pTNM stage in colorectal cancer patients. Hum Pathol. 2014;45(2):268-275.
74. Swinson DE, Jones JL, Richardson D, Cox G, Edwards JG, O'Byrne KJ. Tumour necrosis is an independent prognostic marker in non-small cell lung cancer: correlation with biological variables. Lung Cancer. 2002;37(3):235-240.

75. Frank I, Blute ML, Cheville JC, Lohse CM, Weaver AL, Zincke H. An outcome prediction model for patients with clear cell renal cell carcinoma treated with radical nephrectomy based on tumor stage, size, grade and necrosis: the SSIGN score. $J$ Urol. 2002;168(6):2395-2400.

76. Langner C, Hutterer G, Chromecki T, Leibl S, Rehak P, Zigeuner R. Tumor necrosis as prognostic indicator in transitional cell carcinoma of the upper urinary tract. $J$ Urol. 2006;176(3):910-913; discussion 913-914.

77. Zigeuner R, Shariat SF, Margulis V, et al. Tumour necrosis is an indicator of aggressive biology in patients with urothelial carcinoma of the upper urinary tract. Eur Urol. 2010;57(4):575-581.

78. Pollheimer MJ, Kornprat P, Lindtner RA, et al. Tumor necrosis is a new promising prognostic factor in colorectal cancer. Hum Pathol. 2010;41(12):1749-1757.

79. Richards $\mathrm{CH}$, Flegg KM, Roxburgh CS, et al. The relationships between cellular components of the peritumoural inflammatory response, clinicopathological characteristics and survival in patients with primary operable colorectal cancer. Br J Cancer. 2012;106(12): 2010-2015.

80. Richards CH, Roxburgh CS, Anderson JH, et al. Prognostic value of tumour necrosis and host inflammatory responses in colorectal cancer. Br J Surg. 2012;99(2):287-294.

81. Komori K, Kanemitsu Y, Kimura K, et al. Tumor necrosis in patients with TNM stage IV colorectal cancer without residual disease (R0 status) is associated with a poor prognosis. Anticancer Res. 2013;33(3):1099-1105.

82. Guthrie GJ, Roxburgh CS, Richards CH, Horgan PG, McMillan DC. Circulating IL-6 concentrations link tumour necrosis and systemic and local inflammatory responses in patients undergoing resection for colorectal cancer. Br J Cancer. 2013;109(1):131-137.

83. Jass JR, Morson BC. Reporting colorectal cancer. J Clin Pathol. 1987;40(9):1016-1023.

84. Klintrup K, Mäkinen JM, Kauppila S, et al. Inflammation and prognosis in colorectal cancer. Eur J Cancer. 2005;41(17) $2645-2654$.

85. Roxburgh CS, Salmond JM, Horgan PG, Oien KA, McMillan DC. Tumour inflammatory infiltrate predicts survival following curative resection for node-negative colorectal cancer. Eur J Cancer. 2009;45(12):2138-2145.

86. Powell AG, Ferguson J, Al-Mulla F, et al. The relationship between genetic profiling, clinicopathological factors and survival in patients undergoing surgery for node-negative colorectal cancer: 10-year follow-up. J Cancer Res Clin Oncol. 2013;139(12):2013-2020.

87. Ogino S, Nosho K, Irahara N, et al. Lymphocytic reaction to colorectal cancer is associated with longer survival, independent of lymph node count, microsatellite instability, and $\mathrm{CpG}$ island methylator phenotype. Clin Cancer Res. 2009;15(20):6412-6420.

88. Shia J, Ellis NA, Paty PB, et al. Value of histopathology in predicting microsatellite instability in hereditary nonpolyposis colorectal cancer and sporadic colorectal cancer. Am J Surg Pathol. 2003;27(11): $1407-1417$.

89. Greenson JK, Huang SC, Herron C, et al. Pathologic predictors of microsatellite instability in colorectal cancer. Am J Surg Pathol. 2009;33(1): 126-133.

90. Nagtegaal ID, Marijnen CA, Kranenbarg EK, et al. Local and distant recurrences in rectal cancer patients are predicted by the nonspecific immune response; specific immune response has only a systemic effect a histopathological and immunohistochemical study. BMC Cancer. 2001;1:7.

91. Deschoolmeester V, Baay M, Van Marck E, et al. Tumor infiltrating lymphocytes: an intriguing player in the survival of colorectal cancer patients. BMC Immunol. 2010;11:19. 
92. Kim YW, Jan KM, Jung DH, Cho MY, Kim NK. Histological inflammatory cell infiltration is associated with the number of lymph nodes retrieved in colorectal cancer. Anticancer Res. 2013;33(11): 5143-5150.

93. Richards CH, Roxburgh CS, Powell AG, Foulis AK, Horgan PG, McMillan DC. The clinical utility of the local inflammatory response in colorectal cancer. Eur J Cancer. 2014;50(2):309-319.

94. Galon J, Costes A, Sanchez-Cabo F, et al. Type, density, and location of immune cells within human colorectal tumors predict clinical outcome. Science. 2006;313(5795):1960-1964.

95. Galon J, Mlecnik B, Bindea G, et al. Towards the introduction of the 'Immunoscore' in the classification of malignant tumours. J Pathol. 2014;232(2):199-209.

96. Lugli A, Karamitopoulou E, Panayiotides I, et al. CD8+ lymphocytes/ tumour-budding index: an independent prognostic factor representing a 'pro-/anti-tumour' approach to tumour host interaction in colorectal cancer. Br J Cancer. 2009;101(8):1382-1392.

97. Nielsen HJ, Hansen U, Christensen IJ, Reimert CM, Brünner N, Moesgaard F. Independent prognostic value of eosinophil and mast cell infiltration in colorectal cancer tissue. J Pathol. 1999;189(4): $487-495$.
98. Fernandez-Acenero MJ, Galindo-Gallego M, Sanz J, Aljama A. Prognostic influence of tumor-associated eosinophilic infiltrate in colorectal carcinoma. Cancer. 2000;88(7):1544-1548.

99. Gulubova M, Ananiev J, Yovchev Y, Julianov A, Karashmalakov A, Vlaykova T. The density of macrophages in colorectal cancer is inversely correlated to TGF- $\beta 1$ expression and patients' survival. J Mol Histol. 2013;44(6):679-692.

100. Forssell J, Oberg A, Henriksson ML, Stenling R, Jung A, Palmqvist R. High macrophage infiltration along the tumor front correlates with improved survival in colon cancer. Clin Cancer Res. 2007;13(5): 1472-1479.

101. Chaput N, Svrcek M, Aupérin A, et al. Tumour-infiltrating CD68+ and CD57+ cells predict patient outcome in stage II-III colorectal cancer. Br J Cancer. 2013;109(4):1013-1022.

\section{Publish your work in this journal}

Cancer Management and Research is an international, peer-reviewed open access journal focusing on cancer research and the optimal use of preventative and integrated treatment interventions to achieve improved outcomes, enhanced survival and quality of life for the cancer patient. The journal welcomes original research, clinical \& epidemiological

\section{Dovepress}

studies, reviews \& evaluations, guidelines, expert opinion \& commentary, case reports \& extended reports. The manuscript management system is completely online and includes a very quick and fair peerreview system, which is all easy to use. Visit http://www.dovepress.com/ testimonials.php to read real quotes from published authors. 